\title{
FRAGILIDADES DA EQUIPE DE ENFERMAGEM E SEUS REFLEXOS NO CONTEXTO HOSPITALAR ORGANIZACIONAL: RELATO DE EXPERIÊNCIA
}

\author{
Taís Leal Machado'; Natália Cassol Bolzan²; Karen Ariane Bar ${ }^{3}$; Solange \\ Aparecida de Azeredo Schafer ${ }^{4}$; Adriana Dall' Asta Pereira ${ }^{5}$
}

\section{RESUMO}

Objetivo: socializar as experiências vivenciadas por estudantes de enfermagem no Serviço de Infecções Relacionadas à Assistência à Saúde e Auditoria de uma instituição hospitalar. Metodologia: Trata-se de um relato de experiência, construído a partir da vivência de alunas em estágio final de graduação no processo de reflexão acerca de vivências referentes à discussão do processo gerencial. Foi realizado durante a disciplina de estágio curricular III, do Curso de Enfermagem da Universidade Franciscana, realizada no período de agosto de 2021, em um Hospital de médio porte, localizado em Santa Maria -RS. Resultados: As vivências dos discentes foram sistematizadas em duas Unidades de discussão: A motivação como instrumento e o trabalho em equipe e consequências ao paciente devido a falhas na equipe e assistência. Considerações Finais: A ação possibilitou a discussão e reflexão em grupo, revisão de temas essenciais e esclarecimento de dúvidas. Para as enfermeiras, foi importante devido à abordagem de incoerências percebidas no cotidiano de trabalho das mesmas. Ao hospital, destaca-se a educação permanete e aperfeiçoamento dos profissionais que nele atuam.

Palavras-chave: Enfermagem; Auditoria; Controle de Infecção Hospitalar

Eixo Temático: Atenção Integral e Promoção à Saúde (AIPS)

\footnotetext{
${ }^{1}$ Taís Leal Machado- Acadêmica de Enfermagem - Universidade Franciscana. taaismachado@gmail.com.

${ }^{2}$ Natalia Cassol Bolzan- Acadêmica de Enfermagem - Universidade Franciscana. Natalia.bolzan@gmail.com.

${ }^{3}$ Karen Ariane Bar - Enfermeira do centro de controle Infecções relacionadas a assistência a saúdeHospital Casa de Saúde - ccih@sefas.org.br.

${ }^{4}$ Solange Aparecida de Azeredo Schafer - Enfermeira Auditora - Hospital Casa de Saúde Schafersolange@gmail.com.

${ }^{5}$ Adriana Pereira Dal'lasta - Docente - Universidade Franciscana Adrianadallastapereira@gmail.com
} 


\section{INTRODUÇÃO}

A realização da auditoria pelo enfermeiro requer numerosos encargos, sendo estes, atuação com ética, conhecimento sobre os processos financeiros do hospital em relação a planos de saúde, conhecimento sobre a atualização de novos produtos, atualização contínua e conhecimento minucioso a respeito da conta e prontuário do paciente (ANDREOTTI, 2017).

No que tange os objetivos da auditoria, é essencial assistir o paciente com qualidade, realizar a cobrança devida de acordo com materiais utilizados na assistência, conter gastos e diminuição de desperdícios. Nesse sentido o enfermeiro auditor pode estar inserido nas ações de educação continuada realizando orientações para a equipe de saúde, para sensibilizá-los sobre a importância do correto preenchimento de dados em prontuário e entre outras ações que podem interferir diretamente no processo de auditagem (ANDREOTTI, 2017).

Nesse aspecto a auditoria também vem para realizar a avaliação dos processos de assistência, com olhar ampliado sobre a mesma, relacionando-a com a coleta de dados e elaboração técnica com a finalidade de identificar também as falhas na assistência de enfermagem, com revisão na sua prática, para planejar processos de educação em saúde para ações de melhoria na assistência. Dentre as falhas da assistência, é concreta a ocorrência de Infecções Relacionadas à Assistência à Saúde (IRAS) e nesse sentido este processo da percepção de erros e planejamento de ações de educação na saúde torna-se essencial (ANDREOTTI, 2017).

As Infecções Relacionadas à Assistência à Saúde (IRAS) são consideradas infecções obtidas durante a prestação da assistência, onde condições com acometimento localizado ou sistêmico são consequências de reações adversas sobre a presença de agentes infecciosos que não estavam presentes ao recebimento do paciente no ambiente assistencial (MELLO; COSTA; HOFFMAN, 2019).

Nesse sentido a ocorrência de IRAS são acontecimentos de extrema 
relevância, devido às infecções apresentarem complicações na assistência aos pacientes, ocasionando causas de morbimortalidade e elevando os custos nos serviços de saúde. Desta forma, estas complicações implicam problemas na assistência prejudicando diretamente na segurança do paciente, sendo este um grande problema de saúde pública (MELLO; COSTA; HOFFMAN, 2019).

Em vista disso, observa-se a relevância de todo o processo e identificação das fragilidades sendo assistenciais quando organizacionais e o papel do enfermeiro neste processo, observando às ações intrínsecas a assistência ao paciente, intervindo de maneira ampliada, evitando iatrogenias no objetivo final, que seria a assistência de qualidade ao paciente.

Sob esse enfoque, acredita-se na relevância e necessidade de socializar as experiências vivenciadas durante o estagio curricular supervisionado, motivo pelo qual se justifica o desenvolvimento deste estudo, realizado a partir da atuação de estudantes de enfermagem no Serviço de Infecções Relacionadas à Assistência à Saúde e Auditoria de uma instituição hospitalar.

\subsection{Objetivo}

Este trabalho tem por objetivo socializar as experiências vivenciadas por discentes durante o Estágio Curricular Supervisionado III, a partir da atuação de estudantes de enfermagem no Serviço de Infecções Relacionadas à Assistência à Saúde e Auditoria de uma instituição hospitalar.

\section{METODOLOGIA}

Trata-se de um relato de experiência, construído a partir da vivência de estudantes durante o Estágio Curricular Supervisionado III nos setores de Auditoria e Comissão de Controle de Infecção Hospitalar (CCIH), em um Hospital de médio porte, $100 \%$ SUS, localizado na região norte, na cidade de Santa Maria, Rio Grande do Sul.

Em primeiro momento foi realizado um diagnóstico situacional, ao revisar os prontuários das unidades do hospital foi possível verificar diversas falhas, tanto em prescrições sem assinatura e sem checagem, falta de evoluções diárias dos 
profissionais, data errada em evoluções e procedimentos, evoluções sem assinaturas, prontuários fora de ordem, folhas não preenchidas e evoluções incompletas. Com base nisso, observou-se que a Unidade Clínica do hospital se destacava de maneira negativa em vários destes aspectos.

Percebeu-se também que havia dificuldades no trabalho em equipe, organização da unidade, hierarquia profissional, postura profissional e aspectos relacionados ao controle de infecções hospitalares, como lavagem das mãos, uso de luvas, higienização de objetos, entre outros, e isso acabava implicando na assistência ao paciente. Dessa forma, resolveu-se fazer uma capacitação com os enfermeiros e técnicos de enfermagem da Unidade Clínica, a qual foi direcionada como ação do Estágio Curricular Supervisionado em Enfermagem III, sob orientação da professora responsável pela disciplina.

O processo de intervenção foi idealizado durante o mês de agosto de 2021 e, na prática, foi aplicado no mês de setembro de 2021. As intervenções foram efetuadas por acadêmicas de Enfermagem no décimo semestre, e contou com o apoio da Enfermeira responsável pela Auditoria hospitalar e da Enfermeira do $\mathrm{CCIH}$.

A capacitação foi realizada em um único dia, com profissionais de todos os turnos, com duração de cerca de 90 minutos. Foi efetuado em uma roda de conversa e alavancaram-se assuntos pertinentes à prática profissional. Os assuntos abordados foram: trabalho em equipe, questões autorreflexivas, condutas de enfermagem, anotações de enfermagem e higienização das mãos.

\section{RESULTADOS E DISCUSSÕES}

As vivências das alunas de enfermagem foram organizadas e sistematizadas em duas Unidades de discussão: A motivação como instrumento e o trabalho em equipe e Consequências ao paciente devido a falhas na equipe e assistência, como mudar este processo.

\subsection{A motivação como instrumento e o trabalho em equipe}

A intervenção ocorreu no auditório do hospital Casa de Saúde, com base nas demandas previamente sugeridas e identificadas pelas acadêmicas e enfermeiras 
supervisoras. A capacitação contou com a participação de profissionais da saúde provenientes dos turnos manhã e tarde. As acadêmicas de enfermagem, juntamente com a enfermeira da Auditoria de Enfermagem e a enfermeira do $\mathrm{CCIH}$, realizaram a intervenção para os profissionais de saúde do hospital a respeito das relações em equipe, anotações de enfermagem e higienização das mãos.

No âmbito da Auditoria em saúde, abordaram-se pontos sobre a importância do trabalho em equipe, evoluções diárias, inconformidades em evoluções, checagem de atividades e o quanto a assistência repercute na gestão. Foi explanado sobre a importância da profissão e questionado o motivo de cada um ter escolhido a mesma, para fazê-los refletir acerca da assistência que está sendo prestada ao usuário. Observou-se, que os colaboradores pensaram sobre o assunto, exteriorizando alguns depoimentos.

Também, foi possível perceber o quanto eles se sentiram parte da equipe a partir das reflexões realizadas pelas acadêmicas e enfermeiras sobre a importância deles nesse processo. Nesse aspecto, a motivação considerada ponto importante na vivência em grupo, reconhecimento, segurança e integração, vêm para criar um ambiente de participação, facilitando a compreensão dos objetivos esperados, considerando estas pessoas capazes de obter os melhores resultados. Nesse sentido a motivação é considerada facilitadora do processo, auxiliando na troca de experiencias, na reflexão das ações e nas mudanças na práxis do cuidado (ARAUJO et. al., 2021).

A auditoria pode ser vista como um processo educativo e auxiliar para gerenciar e implantar uma assistência de qualidade. Com isso, pode-se focar nos problemas cotidianos para nortear ações pertinentes ao gerenciamento do sistema de saúde (LOUREIRO et al., 2018).

Nesse sentido, esta é uma especialidade que se dedica a eficiência e eficácia dos serviços prestados ao usuário, avalia e revisa detalhadamente os prontuários e anotações e faz o controle e a análise de registros. Porém, um dos elementos principais do processo da auditoria são os prontuários, pois a partir dele pode-se avaliar a qualidade da assistência prestada, além de ser uma ferramenta legal aos profissionais e instituições (BONFIM, 2020). 
No que diz respeito a assuntos de relevância pontuados para serem tratados pelo $\mathrm{CCIH}$, foi explanado sobre prioritariamente à segurança do paciente, ela um conjunto de várias ações de prevenção e cuidado na assistência direta ao paciente, incluindo a importância do uso correto de luvas e os momentos apropriados para tal.

Nesse sentido, também foi pontuado a importância da lavagem das mãos na assistência indireta e direta ao paciente, tanto quanto os objetos e superfícies próximas ao paciente. Estas são ações que quando bem realizadas são formas eficazes na prevenção de infecções e transmissibilidade de microrganismos ao paciente.

\subsubsection{Consequências ao paciente devido a falhas na equipe e} assistência, como mudar este processo

A assistência em saúde traz consigo a possibilidade de melhora clínica do paciente, porém, também apresenta riscos no que tange a contaminação por microrganismos no período de internação. Riscos provenientes de falhas assépticas, ausência da higienização das mãos e da conscientização dos riscos caso esta não ocorra gerando ocorrências que podem ser apresentadas por conta disso.

Nesse sentido, em prol da segurança do paciente, se junta o $\mathrm{CCIH}$, com a equipe de enfermeiros de todos os setores existentes por meio da educação permanente para tratar de assuntos relacionados ao principal veículo de transmissão de infecções, os quais são; as mãos e as vestimentas dos profissionais. Nesse sentido a equipe de enfermagem deve estar atenta aos meios desencadeantes de infecções, realizando intervenções para a prevenção da ocorrência destas e de demais agravos (HOYASHI et al., 2017).

Deve-se estar atento aos fatores extrínsecos ao paciente, sendo estes congruentes ao meio externo, como; Higienização das mãos, técnicas corretas durante a realização de procedimentos invasivos, uso correto de equipamentos de proteção individual. Como procedimento de maior influência na prática, a higienização das mãos $(\mathrm{HM})$ é a prática mais eficaz para reduzir as infecções relacionadas à assistência à saúde (IRAS), pois evita a transmissão de microrganismos. Sendo então a HM o principal fator extrínseco de interesse e relevância (HOYASHI et al., 2017). 
Sendo a prática mais efetiva para o controle de transmissão de infecção, a higiene das mãos a qual é práxis de difícil adesão pelos profissionais, resultando em uma problemática de difícil controle. Neste aspecto é necessário o treinamento das equipes e colaboradores pontuando a importância desta ação promovendo a conscientização e responsabilidade da equipe para que desta forma reduza os níveis de infeção (HOYASHI et al., 2017).

O controle de infecções juntamente com a conscientização dos profissionais presentes no cuidado diário ao paciente deve ser evidenciado aos colaboradores para garantir a manutenção e prevenção de agravos prezando pela segurança no ambiente hospitalar (HOYASHI et al., 2017).

\section{CONCLUSÃO}

Este estudo descreveu a realização de uma capacitação com uma unidade clínica assistencial de um hospital, a qual foi idealizada por acadêmicas de enfermagem como ação de estágio final de graduação. Foi possível demonstrar a importância do olhar crítico enquanto estudantes de enfermagem e como tentaram solucionar tais inconformidades encontradas.

Destaca-se que a ação foi importante tanto para os profissionais da unidade clínica que participaram da capacitação, quanto para as enfermeiras supervisoras, para o hospital e às estagiárias. Aos profissionais, possibilitou a discussão e reflexão em grupo, novos conhecimentos, revisão de temas essenciais e esclarecimento de dúvidas. Para as enfermeiras, foi importante devido à abordagem de incoerências percebidas no cotidiano de trabalho das mesmas. Ao hospital, destaca-se a educação continuada e aperfeiçoamento dos profissionais que nele atuam.

E por fim, os ensinamentos adquiridos nessa vivência proporcionaram novos horizontes e perspectivas enquanto acadêmicas e futuras profissionais, possibilitando um desenvolvimento pessoal e profissional à frente da equipe. 


\section{REFERÊNCIAS}

ANDREOTTI, E.T.; FONTE, M. A.; IPUCHIMA, C. C. K. Auditoria concorrente de enfermagem em prestadores de assistência à saúde: uma revisão integrativa da literatura. Rev. Adm. Saúde, v. 17, n 68, set 2017 Vol. 17, Nº 68, Jul. - Set. 2017. Disponível em: https://cqh.org.br/ojs-2.4.8/index.php/ras/article/view/41. Acesso em 20 de agosto 2021.

ARAUJO, M.C.C.; ACIOLI, S.;NETO,M.; MELLO, A.S.;BRANDÃO, P.S. Protocolos de enfermagem: construção compartilhada. Revista Enfermagem UERJ, [S.I.], v. 25, p. e27339, abr. 2017.. Disponível em: <https://www.epublicacoes.uerj.br/index.php/enfermagemuerj/article/view/27339>. Acesso em: 29 set. 2021.

BONFIM, G. S. O papel do enfermeiro na auditoria hospitalar. Id on Line Rev. Mult. Psic. V.14, N. 52, p. 558-563, 2020. Disponível em: https://idonline.emnuvens.com.br/id/article/view/2732/4337. Acesso em 20 agosto 2021.

HOYASHI, C. M.T.; SILVA, P. S.; SILVA, R. M.; SILVA, T. R. Prevenção e controle de infecções relacionadas à assistência à saúde: fatores extrínsecos ao paciente. HU rev. v. 43, n. 3, p. 277-283, jul./set. 2017. Disponível em: https://docs.bvsalud.org/biblioref/2018/10/947537/2739-18239-6-pb.pdf. Acesso em 18 de agosto de 2021.

LOUREIRO, L. H.; COSTA, L. M.; MARQUES, V. L.; HOYASHI, C. M. T. Como a auditoria de enfermagem pode influenciar na qualidade assistencial. Revista Práxis, v. 10, n. 19, p. 1-102, 2018. Disponível em: https://moodleead.unifoa.edu.br/revistas/index.php/praxis/article/view/698/1621. Acesso em 20 agosto 2021. 


\section{QUFN}

MELLO, M. S.; COSTA, R. S. M.; HOFFMANN, A. M.; Auditoria do serviço de controle de infecção hospitalar: boa prática para avaliar a antibioticoprofilaxia no tempo adequado através de ferramentas de gestão. Revista Interdisciplinar Ciências Médicas v. $3, \quad$ n 1, p. 10-17 - 2019. Disponível em: http://revista.fcmmg.br/ojs/index.php/ricm/article/view/85. Acesso em 18 de agosto de 2021. 